\title{
Experimental Investigation on the Drying of Loosely-Packed and Heterogeneous Municipal Solid Waste ${ }^{1}$
}

\author{
A. M. Nzioka ${ }^{a}$, M. G. Kim ${ }^{a}$, H. U. Hwang ${ }^{a}$, C. Z. Yan ${ }^{a}$, V. E. Ved ${ }^{b}$, V. P. Meshalkin ${ }^{c}$, and Y. J. Kim, \\ ${ }^{a}$ Kyungpook National University, Daegu, Republic of Korea \\ ${ }^{b}$ National Technical University, "Kharkov Polytechnic Institute”, Ukraine \\ ${ }^{C} D$. Mendeleev University of Chemical Technology of Russia, Russian Federation \\ *e-mail: yjukim@knu.ac.kr \\ Received February 27, 2016
}

\begin{abstract}
In this paper, experimental investigation on convective drying of mixed municipal solid wastes was conducted. The aim of this study was to determine the effect of temperature, change in composition and particle size on the overall drying rate coefficient and mass transfer coefficient. Particle size of the samples was determined and mass losses recorded with time when the samples were dried using convective dryer. Mass losses were used to determine moisture content, drying rate coefficient and mass transfer coefficient. Experimental results showing the effect of temperature, changes in the composition of organic waste and particle size were presented.
\end{abstract}

Keywords: municipal solid waste, convective drying, drying rate coefficient, particle size, composition

DOI: $10.1134 / \mathrm{S} 0040579516040448$

\section{INTRODUCTION}

Municipal Solid Wastes (MSW) generated in developing and emerging countries has received significant attention these days due to the negative impacts associated with management and disposal. Some of the negative impacts, as noted by several authors [1-4], include negative environmental and health impact related to collection, transport and disposal of MSW in aforesaid countries due to the heterogeneous nature of MSW. UNEP and Cal Recovery Inc. among other authors noted that MSW generated in middle and lower-income Countries is usually unsorted from the point of generation and contains relatively high water content [4]. Therefore, due to difficulties of recycling MSW in this form using existing recycling methods, majority of countries have resorted to landfiling as an economically viable option. However, landfiling, as stipulated by several authors, has been a source of various forms of pollution thereby creating more economic costs and liabilities $[1,2,5$, 6]. In order to address the negative impacts of mixed MSW, several solutions have been proposed. Thermocatalytic incineration complex proposed by Ved et al. is part of the solution that is designed to solve the problem through complete MSW incineration with catalytic removal of toxic compounds from exhaust air after incineration process [7]. Other solutions that include policy incentives [8] as well as Optimal MSW

${ }^{1}$ The article is published in the original. management $[9,10]$ have been proposed and implemented in different developing and Emerging Countries. The aforesaid proposals as well as continuing research have focused on resolving the negative effects of mixed MSW with considerably high water content.

On the other hand, mixed MSW from Developing and Emerging Countries (e.g. Kenya) is a source of calorific hydrocarbons which could be reutilized as energy resources. Proximate analysis conducted by different authors [11-13] showed that mixed MSW generated in Nairobi, Kenya mainly consist of combustible hydrocarbons as shown in Table 1. However, due to the high moisture content, thermal processing becomes uneconomical thereby relying on other conventional processes such as bio-drying $[14,16]$. Investigations done by He et al. [14] among other authors have mainly focused on bio-drying as the optimal alternative for converting high-moisture mixed MSW to useful resource.

However, with the development and application of Process Integration in other energy intensive industries $[15,17]$, recuperation and reutilization of waste heat for other useful processes becoming economically feasible and resource efficiency enhanced. Therefore, thermal conversion of mixed MSW to Refuse Derived Fuel (RDF) using waste heat from other energy-intensive chemical processes has become perspective. This has been proven by Troshin et al among other authors [20]. The aforementioned author proposed process which could convert high-moisture mixed MSW to 
Table 1. Typical composition of mixed municipal wastes generated in Nairobi, Kenya

\begin{tabular}{l|c|c|c}
\hline \multirow{2}{*}{ Components } & \multicolumn{3}{|c}{ Composition } \\
\cline { 2 - 4 } & cited in [11] & cited in [13] & cited in [12] \\
\hline Organics & $50-57$ & $50.6-58$ & $43-50.9$ \\
Paper & $16-17.3$ & $17-17.5$ & $12.1-17.5$ \\
Plastics & $11.8-14$ & $12-16.1$ & $15.1-16.1$ \\
Glass & $2-2.3$ & 2 & $2-5.6$ \\
Metal & $1-3$ & $2-3$ & $2-2.7$ \\
Wood/grass & $2-8$ & - & - \\
Leather & $0.9-1$ & - & - \\
Rubber & $2-2.3$ & - & - \\
Textiles & $2-2.7$ & - & - \\
Others & $2.7-7$ & - & $11.4-21.7$ \\
\hline
\end{tabular}

RDF while reducing significantly toxic substance through Process Integration of MSW-to-RDF production process with Portland Cement Clinker production process. This proposal relies on convective drying as one of the main technological process. It is due to perceived economic insignificance of convective drying that majority of the studies conducted were mainly focused on bio-drying of high-moisture mixed MSW than on convective drying. Therefore, knowledge related to convective drying of mixed MSW will be inherent. Several studies related to drying process have been conducted. Padokhin et al. [18] analyzed heat and mass transfer process during drying process of an infinite cylindrical object. Afanas'ev and Siplivyi [19] analyzed transport phenomena for a cylindrical object subjected to constant drying rate using electromagnetic drying. Results of the aforesaid studies among others have does not provide sufficient explanation with respect to mixed MSW. In particular, the effects of various factors such as temperature, particle size and composition of mixed MSW on drying rate coefficient have not been conducted.

The motivation behind this study was to determine the effect of temperature, varying composition and particle size on the overall drying rate coefficient and mass transfer coefficient of mixed MSW. Mathematical formulation for drying rate will be derived as well as detailed explanation of the experiment will be given.

\section{MATERIALS AND METHODS}

Drying rate kinetics. Drying process for typical material could be classified into three categories, namely: initial drying period, constant drying rate period and falling drying rate period. For materials with high moisture, initial period could be neglected. In this particular study, structural, thermal and thermodynamic properties are considered to be a function of drying rate coefficient. Therefore, overall drying rate coefficient and mass transfer coefficient will be considered constant for first and second drying period using methodology proposed by [21]. This methodology proposed by Strumillo et al [21] enables to describe overall drying process using single kinetic equation which could be determined from drying curve and boundary equations. Kinetics of the drying curve may be described using the following expression [21]:

$$
\frac{d X}{d t}=K\left(X-X_{\text {eq }}\right) \text {. }
$$

Where, $K$ represents the drying rate coefficient while $X$ and $X_{\text {eq }}$ represent final moisture and final equilibrium moisture content respectively. However, due to high moisture composition of the main component (organic waste), then the overall drying kinetics could be limited to the constant drying period. Therefore, from mass transfer equation, $\frac{d X}{d t}=$ $K\left(X_{1}-X\right)\left(X-X_{\mathrm{eq}}\right)$, integral form of this equation will give the following expression [21]:

$$
t=\frac{1}{K\left(X_{1}-X_{\mathrm{eq}}\right)} z
$$

where, $z$ is a parameter determined using the following expression:

$$
z=\ln \frac{\left(X_{1}-X\right)\left(X_{\text {eq }}-X_{\mathrm{eq}}\right)}{\left(X_{1}-X_{\mathrm{eq}}\right)\left(X-X_{\mathrm{eq}}\right)} .
$$

In the expressions above, $K$ represents the drying rate coefficient, $X_{\text {eq }}$-final equilibrium moisture content $X_{1 \text { eq }}$-initial equilibrium moisture content and $X-$ final moisture content. Drying kinetics curve on $t-z$ coordinates will exhibit a linear relation with a slope equivalent to $K$ (Drying rate coefficient). For cases where $X_{1 \mathrm{eq}}<X_{1}$, variable $X_{\text {leq }}$ could be determined from the following set of expressions proposed by Strumillo et al. [21]:

$$
\psi=\frac{\left(X_{\mathrm{leq}}-X_{\mathrm{eq}}\right)}{\left(X_{1}-X_{\mathrm{leq}}\right)} e^{z}, \quad X_{\mathrm{leq}}=\frac{\left(X_{1}+X_{\mathrm{eq}}\right)}{(1+\psi)} .
$$

Where parameter $\psi$ is the intermediate parameter for $X_{1 \text { eq }}$ and $z$ is the intercept value on the $z$ axis on the $t-$ $z$ diagram. Therefore, mass transfer coefficient for the overall process could be determined as follows:

$$
k_{\mathrm{d}}=\frac{m_{\mathrm{s}}}{A} K \Delta X \text {. }
$$

Experimental apparatus and materials. Sample materials composed of organic waste, paper, plastics, wood and soil. The aforesaid materials were used as representation of typical composition of waste generated in developing and emerging countries and were analyzed in the experiment on as-received basis.

In accomplishing the objectives of this study, several limitations were considered: there was limited statistical data regarding proximate composition of 
MSW; MSW generated is usually heterogeneous, with varying composition of all components including water content; the flaky nature of mixed waste reduces uniformity of overall composition in the MSW. Putting into consideration the aforementioned limitations, available data suggested by [11-13] were used as the basis for calculation. The samples used were reduced in size with the aim of ensuring uniformity in composition after mixing. Particle size range of the mixed waste analyzed was determined based on the recommendation proposed by Athanasopoulos G.A. [23]. Particle sizes were determined using formula proposed by Keey R.B. [22] whereby the equivalent diameter of a flaky material (MSW) could be determined by the volume it displaces. Therefore, the equivalent diameter $\left(d_{\mathrm{e}}\right)$ of the mixed waste was determined using the following equation [22]:

$$
d_{\mathrm{e}}=\left(\frac{6}{\pi} V\right)^{\frac{1}{3}},
$$

where, $V$ represents the volume displaced by mixed wastes, which may be determined using the following equation:

$$
V=\alpha d_{p}^{3}
$$

Parameter $d_{\mathrm{p}}$ was determined using the expression suggested by Keey R.B. and could be expressed as follows:

$$
d_{\mathrm{p}}=\left(\frac{4}{\pi} B L\right)^{0.5}
$$

where variables $B$ and $L$ represent length and breath of the wastes analyzed.

Organic waste was obtained from the University's dining hall, paper composition consisted of shredded paper and the plastic composition composed of plastic stuffing used in packaging. Soil used was obtained from University's territory while the wood chips represented the wood composition in the experiment. The drying equipment used for this experimental investigation was convective drying oven (Han Baek HB502L). A schematic diagram of the experimental setup is shown in Fig. 1. In order to achieve all the objectives of this experimental study, a set of 4 samples each weighing $100 \mathrm{gr}$. of mixed MSW were used to analyse mass losses and/ or mass transfer coefficient with time. One more sample was used to analyse overall moisture content in the mixed MSW.

During experiment, each sample was put in a wire mesh $(150 \mathrm{~mm} \times 100 \mathrm{~mm} \times 50 \mathrm{~mm})$ such that the thickness of the sample layer analyzed did not exceed $30 \mathrm{~mm}$. The wire mesh plus the sample were placed in the middle of the oven and mass losses were recorded on real-time basis using digital balance (Sartorius TE 612-L). In this experiment moisture content was

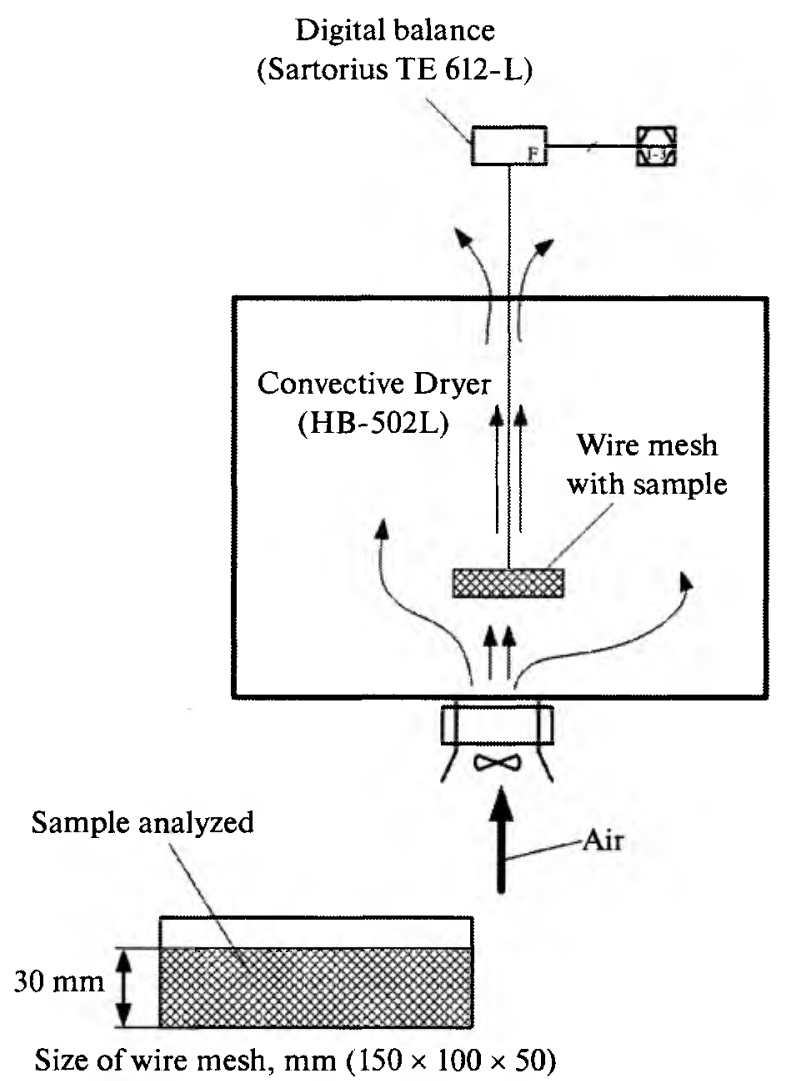

Fig. 1. Schematic diagram of the experimental setup for this study.

derived as a function of mass losses and was calculated using the following equation [15]:

$$
X=\frac{W_{\mathrm{is}}-W_{\mathrm{ds}}}{W_{\mathrm{ds}}} \times 100,
$$

where $X$ is moisture content, $W_{\text {is }}$-initial sample mass, $W_{\mathrm{ds}}$ - mass of dried waste. Moisture content was measured as a \% per dry weight of sample waste. Overall moisture content for sample used was obtained by drying the separate sample in the drying oven (Han Baek $\mathrm{HB}-502 \mathrm{~L}$ ) at a temperature of $105^{\circ} \mathrm{C}$ for 2 hours. The residual moisture content was calculated by means using the eq. (9) above.

Drying rate coefficient $K$ was obtained by determining the slope $t-z$ diagram which exhibit linear relationship. Values for parameter $z$ were obtained using equation (3) and (4). While mass transfer coefficient $k_{\mathrm{d}}$ was calculated using equation (5).

\section{RESULTS AND DISCUSSION}

Effect of temperature on drying. In order to investigate the effect of temperature on drying 5 different temperatures were randomly selected between $50^{\circ} \mathrm{C}$ 
Table 2. Mixture ratio in percentage by weight of the components used in sample for the experimental investigation

\begin{tabular}{l|c|c|c|c|c|c|c}
\hline \multicolumn{7}{c}{ Effect of Temperature } \\
\hline \multirow{2}{*}{ sample name } & particle size, $\mathrm{mm}$ & \multirow{2}{*}{$T,{ }^{\circ} \mathrm{C}$} & \multicolumn{5}{|c}{ composition, \% weight } \\
\cline { 4 - 8 } & & & organic waste & paper & plastic & wood & soil \\
\hline G2 & $<20$ & 60 & 60 & 15 & 15 & 5 & 5 \\
G3 & $<20$ & 70 & 60 & 15 & 15 & 5 & 5 \\
G4 & $<20$ & 80 & 60 & 15 & 15 & 5 & 5 \\
G5 & $<20$ & 90 & 60 & 15 & 15 & 5 & 5 \\
G6 & $<20$ & 100 & 60 & 15 & 15 & 5 & 5 \\
\hline
\end{tabular}

Effect of composition

\begin{tabular}{l|c|c|c|c|c|c|c}
\hline \multirow{2}{*}{ sample name } & \multirow{2}{*}{ particle size, $\mathrm{mm}$} & \multirow{2}{*}{$T,{ }^{\circ} \mathrm{C}$} & \multicolumn{5}{|c}{ composition, \% weight } \\
\cline { 4 - 8 } & & & organic waste & paper & plastic & wood & soil \\
\hline $\mathrm{G} 7$ & $<20$ & $60,80,100$ & 50 & 20 & 15 & 10 & 5 \\
$\mathrm{G} 8$ & $<20$ & $60,80,100$ & 70 & 15 & 10 & 5 & 5 \\
G10 & $<20$ & $60,80,100$ & 60 & 15 & 15 & 5 & 5 \\
\hline
\end{tabular}

Effect of particle size

\begin{tabular}{l|c|c|c|c|c|c|c}
\hline \multirow{2}{*}{ sample name } & \multirow{2}{*}{ particle size, $\mathrm{mm}$} & \multicolumn{2}{|c|}{$T,{ }^{\circ} \mathrm{C}$} & \multicolumn{5}{|c}{ composition, \% weight } \\
\cline { 3 - 8 } & & & organic waste & paper & plastic & wood & soil \\
\hline G10 & $<20$ & $60,80,100$ & 60 & 15 & 15 & 5 & 5 \\
G9 & $>20$ & $60,80,100$ & 60 & 15 & 15 & 5 & 5 \\
\hline
\end{tabular}

and $100^{\circ} \mathrm{C}$, i.e. $60,70,80,90$ and $100^{\circ} \mathrm{C}$. These set of temperatures were chosen based on guidelines for laboratory testing of MSW [23]. A set of 4 samples with similar weight ( 100 gr.) were used in the experimental investigation for each temperature for $30 \mathrm{~min}$. The mean particle size for sample used, determined using expression above, was $<20 \mathrm{~mm}$. Ratio by weight of the components in the sample analyzed is shown in Table 2. Results are shown in Fig. 2 and the average drying rate coefficient and mass transfer coefficient values are shown in Table 3. (Fig. 2) Result showed that the mass transfer coefficient correlated positively with an increase in temperature from 60 to $100^{\circ} \mathrm{C}$. This was attributed to the increase in the rate of mass transfer (moisture diffusivity) through the solids as a result of the increase in temperature which correlates with investigations conducted by other authors [22, 24]. Results presented in Table 3 indicated that mass transfer coefficient at $100^{\circ} \mathrm{C}$ was 2 times higher that at $60^{\circ} \mathrm{C}$. This indicated that higher temperatures were suitable for sustainable drying.

Effect of changes in composition on drying. Internal structure of any dried material among other factors is known to affect drying rate coefficient $[22,24]$. In the sample analyzed, organic waste was considered to be the main component of interest since the moisture content accumulated mainly depends on the internal structure. This experimental analysis was conducted by varying the composition of organic wastes. 3 different sets of sample wastes of with different composition were analyzed and their respective mixture ratios by weight are shown in Table 2 . These set of samples were investigated at 60,80 and at $100^{\circ} \mathrm{C}$ respectively.

At $60^{\circ} \mathrm{C}, \mathrm{G} 10$ samples had a significantly higher rate than $G 8$ and $G 7$ samples despite minimal difference in moisture content. Graphical dependence between moisture content with time is shown in Fig. 3a while values $K$ and $k_{\mathrm{d}}$ are shown in Table 3 . This could be as a result of the difference in the structure of organic waste which also contributed to the difference in drying rates. In addition, low temperature of the drying agent was not sufficient enough to increase the steam saturation pressure on the surface of the organic materials.

At $80^{\circ} \mathrm{C}$ overall drying rate coefficient for sample $\mathrm{G} 7$ was higher than the rest despite the differences in composition of organic waste and moisture content. The same trend also applied to mass transfer coefficient (Table 3 ). From results (Fig. 3b, Table 3 ) the order of drying rates were $\mathrm{G} 7>\mathrm{G} 8>\mathrm{G} 10$. This also indicated that internal structure o organic waste played significant roles in drying process.

Results for experimental analysis conducted at $100^{\circ} \mathrm{C}$ are shown in Fig. $3 \mathrm{c}$ and Table 3. All the samples exhibited different drying rate coefficients and mass transfer coefficients. It was therefore difficult to 
Table 3. Experimental results showing the effect of temperature, changes in composition and particle size on drying rate coefficient and mass transfer rate

\begin{tabular}{|c|c|c|c|c|}
\hline \multicolumn{5}{|c|}{ Effect of temperature drying } \\
\hline sample name & investigated temperature, ${ }^{\circ} \mathrm{C}$ & moisture content, $\%$ & $K, \mathrm{~L} / \mathrm{s}$ & $k_{\mathrm{d}}, \mathrm{kg} /\left(\mathrm{m}^{2} \mathrm{~s}\right)$ \\
\hline$\overline{\mathrm{G} 2}$ & 60 & 57 & 0.16 & 0.167 \\
\hline$\overline{\mathrm{G} 3}$ & 70 & 70 & 0.172 & 0.22 \\
\hline G4 & 80 & 54 & 0.183 & 0.24 \\
\hline$\overline{\text { G5 }}$ & 90 & 64 & 0.193 & 0.3 \\
\hline G6 & 100 & 59 & 0.196 & 0.33 \\
\hline \multicolumn{5}{|c|}{ Effect of composition } \\
\hline sample name & investigated temperature, ${ }^{\circ} \mathrm{C}$ & water content, $\%$ & $K, \mathrm{~L} / \mathrm{s}$ & $k_{\mathrm{d}}, \mathrm{kg} /\left(\mathrm{m}^{2} \mathrm{~s}\right)$ \\
\hline G7 & \multirow{3}{*}{60} & 62 & 0.145 & 0.125 \\
\hline$\overline{\text { G8 }}$ & & 62 & 0.15 & 0139 \\
\hline G10 & & 57 & 0.16 & 0.168 \\
\hline$\overline{\text { G7 }}$ & \multirow{3}{*}{80} & 47 & 0.161 & 0.257 \\
\hline G8 & & 54 & 0.169 & 0.225 \\
\hline G10 & & 56 & 0.186 & 0.192 \\
\hline G7 & \multirow{3}{*}{100} & 70 & 0.144 & 0.211 \\
\hline G8 & & 70 & 0.152 & 0.262 \\
\hline G10 & & 57 & 0.18 & 0.3 \\
\hline \multicolumn{5}{|c|}{ Effect of particle size } \\
\hline G9 & \multirow{2}{*}{60} & 57 & 0.142 & 0.116 \\
\hline G10 & & 48 & 0.16 & 0.168 \\
\hline G9 & \multirow{2}{*}{80} & 57 & 0.144 & 0.18 \\
\hline G10 & & 61 & 0.166 & 0.227 \\
\hline G9 & \multirow{2}{*}{100} & 48 & 0.162 & 0.194 \\
\hline G10 & & 60 & 0.187 & 0.318 \\
\hline
\end{tabular}

develop any correlation between composition of organic waste and drying rate coefficient of samples. The differences in the experimental results could be due to changes in internal and external structures of samples that affect the drying process.

Effect of particle size on drying. In order to investigate the effect of particle size on the drying, two sets of samples were analyzed with different particle sizes determined as shown before; particle size for sample/s G9 was $>20 \mathrm{~mm}$ while sample G2 was $<20 \mathrm{~mm}$ as shown in Table 2 . These samples were investigated at 60,80 and at $100^{\circ} \mathrm{C}$ respectively. Results for experiments conducted at $60^{\circ} \mathrm{C}$ are shown in Fig. 4a and Table 3. Experimental results samples G10 had a higher rate than sample G9. Low drying rate coefficient and mass transfer coefficient for sample with $>20 \mathrm{~mm}$ particle size was attributed to low specific surface area which affected the moisture diffusivity. However, the difference in value $K$ and $k_{\mathrm{d}}$ was not significant enough due to low temperature. At higher temperatures, similar trend as evidenced at $60^{\circ} \mathrm{C}$ was observed with the drying rate increasing with an increase in temperature. Similar trend was also seen at 80 and at $100^{\circ} \mathrm{C}$. Results for experiment conducted at $80^{\circ} \mathrm{C}$ are presented in

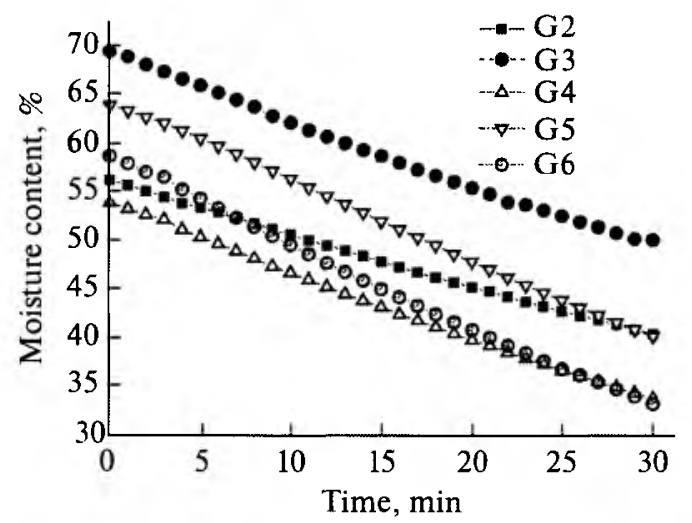

Fig. 2. Dependence of Moisture content on temperature rate conducted at temperature ranging from 60 to $100^{\circ} \mathrm{C}$. 
(a)

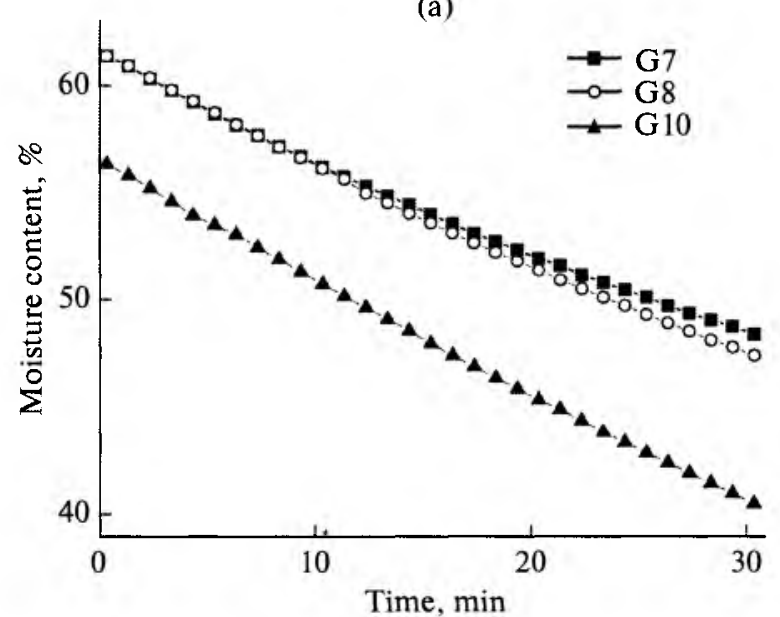

(b)

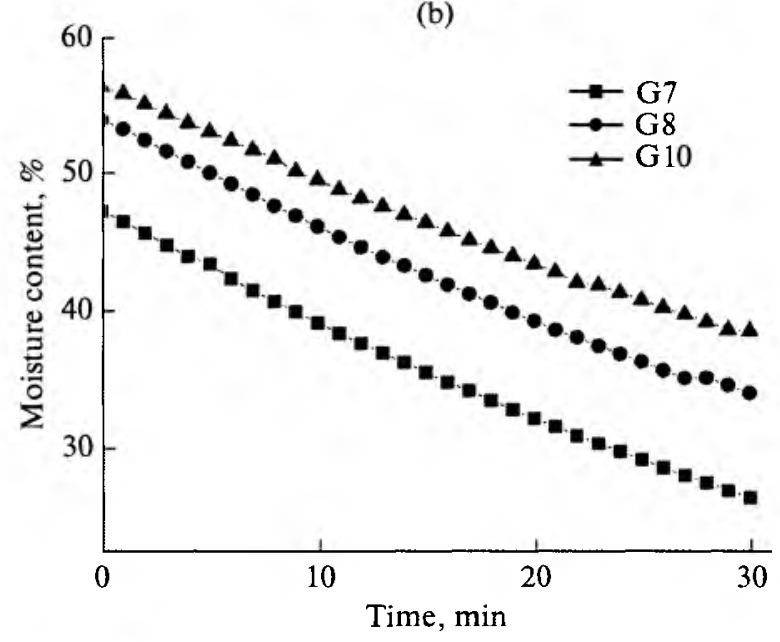

(c)

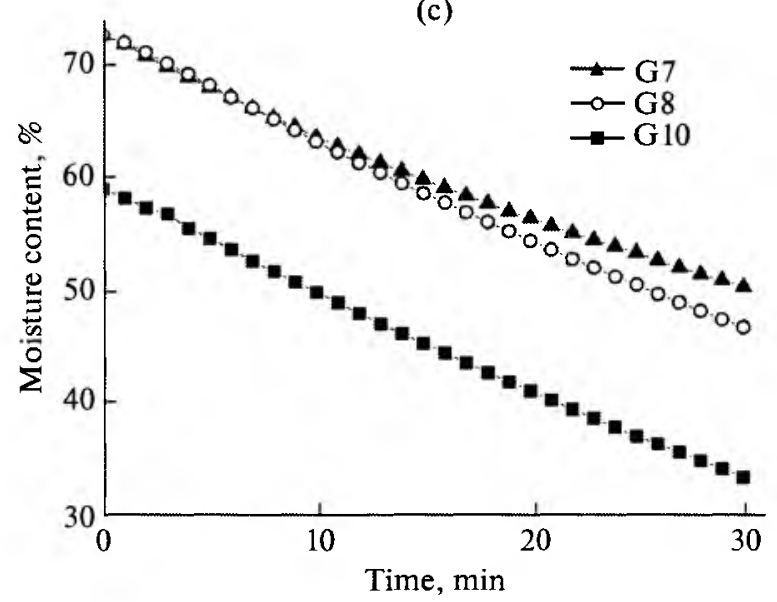

Fig. 3. Graphical dependence of moisture content on changes on composition of organic waste at (a) 60 ; (b) 80 ; (c) $100^{\circ} \mathrm{C}$.

Fig. $4 \mathrm{~b}$ and Table 3 while results for experiment conducted at $100^{\circ} \mathrm{C}$ are presented in Fig. $4 \mathrm{c}$ and Table 3. Higher mass transfer coefficient for samples with

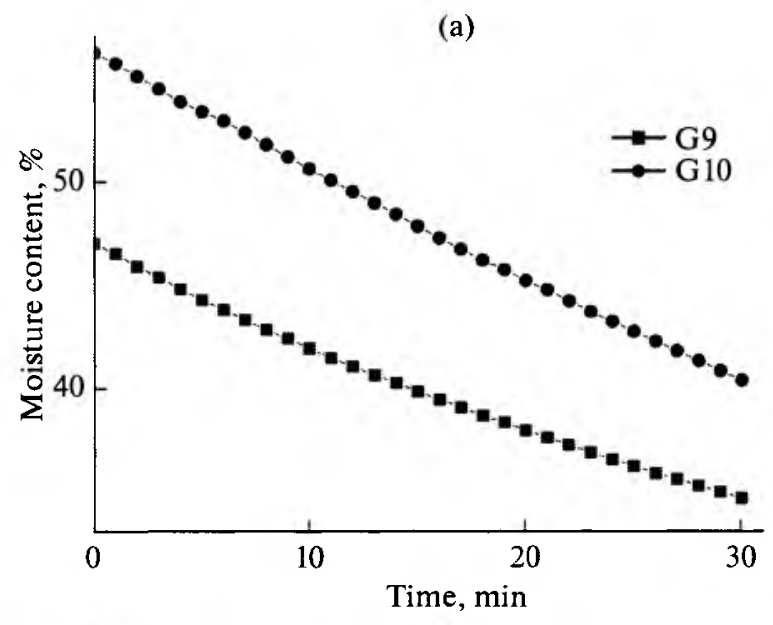

(b)

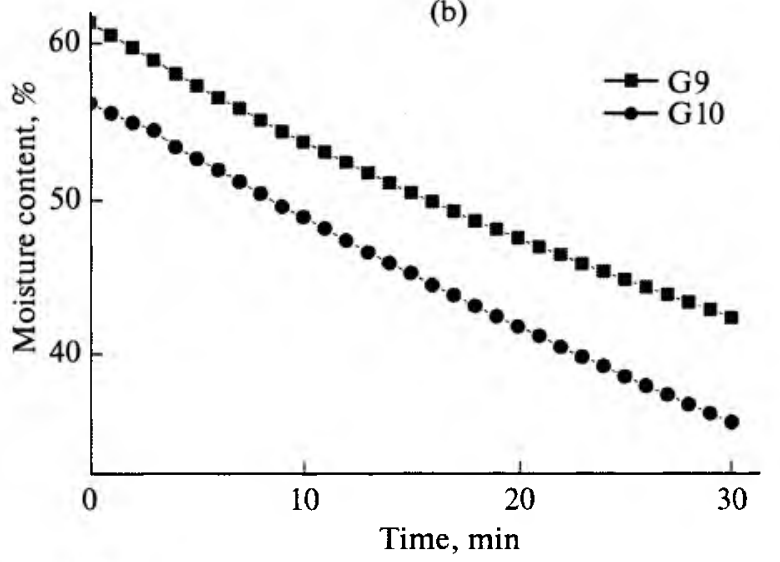

(c)

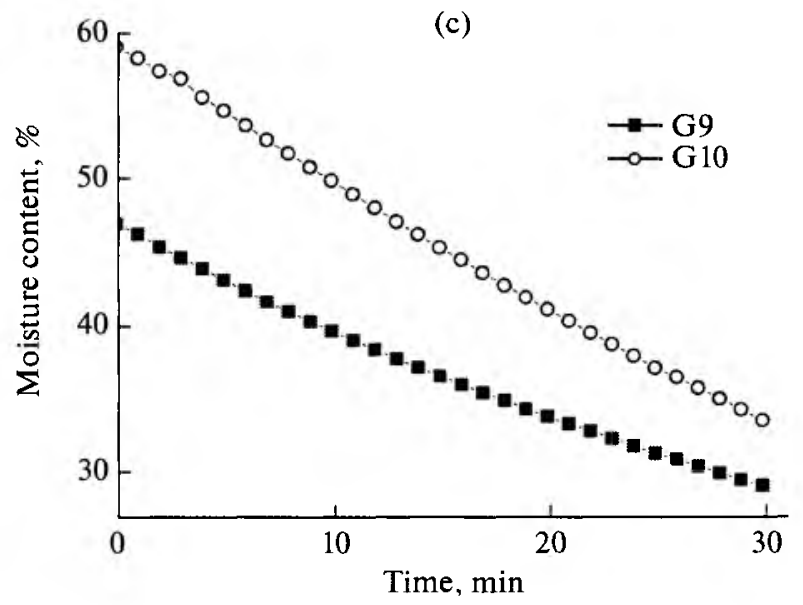

Fig. 4. Graphical dependence of moisture content on particle size at (a) 60 ; (b) 80 ; (c) $100^{\circ} \mathrm{C}$.

$<20 \mathrm{~mm}$ particle size was also attributed to the porous structure created by the presence of plastics which enhanced easier penetration of drying agent. As a result, contact between the surfaces and drying agent is increased thereby increasing saturation pressure of 
steam on the surface of the material which increases the drying rate.

\section{CONCLUSIONS}

Experimental investigation on the effects of temperature, composition and particle size on the drying rate was conducted, drying rate coefficient and mass transfer coefficients were obtained for all cases. Results from experimental investigation showed that temperature increase had positive correlation on drying rate and that it played a significant role in overall drying process; higher drying rates could be achieved at higher temperatures. Difference in particle sizes also played an important role in drying rate. In particular the role of smaller particles in creating porous structure which enhanced drying process was exhibited. Future research will be conducted to investigate the effects of particle size and porous structure on the dynamics of drying.

Data showing the effect of composition on drying rate was sufficient enough to highlight the importance of studying dynamics of drying process for heterogeneous wastes such as mixed MSW. Therefore, future research will be focussed on understanding the role of internal structure on drying process as well as the effect of particle sized and shapes. In addition the shrinking effect of organic wastes in drying process will be investigated.

In addition, experimental data showed the viability of conducting drying process at $100^{\circ} \mathrm{C}$. Therefore, future studies will focus on the optimization of the drying process.

\section{ACKNOWLEDGMENTS}

The authors would like to acknowledge the support granted by NIIED, Republic of Korea.

\section{NOTATION}

$\begin{array}{ll}A & \text { area, } \mathrm{m}^{2} ; \\ B & \text { width, } \mathrm{m} ; \\ d & \text { diameter, } \mathrm{m} ; \\ K & \text { drying rate coefficient, } 1 / \mathrm{s} ; \\ k & \text { mass transfer coefficient, } \mathrm{kg} /\left(\mathrm{m}^{2} \mathrm{~s}\right) \\ L & \text { length, } \mathrm{m} ; \\ m & \text { mass, } \mathrm{kg} ; \\ T & \text { temperature }, \mathrm{C} \\ t & \text { time, } \mathrm{s} ; \\ V & \text { volume, } \mathrm{m}^{3} ; \\ W & \text { sample mass, } \mathrm{g} ; \\ X & \text { moisture content, } \% ; \\ z & \text { variable determined in Eqs. (2) and (3); }\end{array}$

efficient used to determine particle size

variable determined in Eq. (4)

\section{SUBSCRIPTS AND SUPERSCRIPTS}

d

e

eq

$\mathrm{p}$

$\mathrm{s}$ initial;

drying;

equivalent;

equilibrium;

particle;

sample.

\section{REFERENCES}

1. Bagchi, A., Post-closure care of engineered municipal solid waste landfills, Waste Manage. Res., 2015, vol. 33, no. 3, pp. 232-240.

2. Cheremisinoff, A., Handbook of Solid Waste Management and Waste Minimization Technologies, New York: Elsevier, 2003.

3. Integrated Solid Waste Management: Engineering Principles and Management Issues, Tchobanoglous, G., Theisen, H., and Vigil, S.A., Eds., New York: McGrawHill, 1993.

4. UNEP, Solid Waste Management, Osaka: UNEP DTIE, 2005.

5. Stapleton, R.M., Pollution A to Z-Abatement to Index, New York: Thomson/Gale, 2003, vol. 2.

6. Rushbrook, P. and Pugh, M., Solid Waste Landfills in Middle- and Lower-Income Countries: A Technical Guide to Planning, Design and Operation, Washington, DC: World Bank, 1999.

7. Tovazhnyanskii, L.L., Ved, V.E., Koshchii, V.A., Rovenskii, A.I., Meshalkin, V.P., and Krasnokutskii, E.V., Effectiveness of operation of sewerage system of mobile complex of thermocatalytic waste treatment, Theor. Found. Chem. Eng., 2011, vol. 45, no. 6, pp. 838-841.

8. Taylor, D.C., Policy incentives to minimize generation of municipal solid waste, Waste Manage. Res., 2000, vol. 18 , no. 5, pp. 406-419.

9. Turan, N.G. and Ergun, O.N., Improving the quality of municipal solid waste compost by using expanded perlite and natural zeolite, Clean: Soil, Air, Water, 2008, vol. 36 , no. 3, pp. 330-334.

10. Ruj, B. and Ghosh, S., Technological aspects for thermal plasma treatment of municipal solid waste-a review, Fuel Process. Technol., 2014, vol. 126, pp. 298308.

11. Rotich, H.K., Zhao, Y., and Dong, J., Municipal waste management challenges in developing countries-Kenyan case study, Waste Manage., 2006, vol. 26, no. 1, pp. 92-100.

12. Kasozi, A. and Blotnittz, H.V., Solid Waste Management in Nairobi: A Situational Analysis, Nairobi: UNEP, 2010.

13. Njoroge, B.N., Kimani, M., and Ndunge, D., Review of municipal solid waste management: A case study of Nairobi, Kenya, Int. J. Eng. Sci., 2014, vol. 4, no. 2, pp. $16-20$. 
14. Zhang, D.Q., He, P.J., and Shao, L.M., Sorting efficiency and combustion properties of municipal solid waste during bio-drying, Waste Manage., 2009, vol. 29, no. 11 , pp. 2816-2823.

15. Ul'ev, L.M. and Vasil'ev, M.A., Heat and power integration of processes for the refinement of coking products, Theor. Found. Chem. Eng., 2015, vol. 49, no. 5, pp. 676-687.

16. Zawadzka, A., Krzystek, L., and Ledakowicz, S., Autothermal biodrying of municipal waste with high moisture content, Chem. Pap., 2010, vol. 64, no. 2, pp. 265268.

17. Meshalkin, V.P., Tovazhnyanskii, L.L., Ul'ev, L.M., Mel'nikovskaya, L.A., and Khodchenko, C.M., Energy and resource-effective reconstruction of crude oil refining equipment based on pinch-analysis with consideration of heat losses, Teor. Osn. Khim. Tekhnol., 2012, vol. 46, no. 5, pp. 491-500.

18. Padokhin, V.A., Kochkina, N.E., Zueva, G.A., Kokurina, G.N., and Fedosov, S.V., Complex mathematical description of heat and mass transfer in the dry- ing of an infinite cylindrical body with analytical methods of heat-conduction theory, Theor. Found. Chem. Eng., 2015, vol. 49, no. 1.pp. 50-60.

19. Afanas'ev, A.M. and Siplivyi, B.N., Theory of electromagnetic drying: An asymptotic solution of an initialboundary value problem of a cylinder, Theor. Found. Chem. Eng., 2014, vol. 48, no. 2, pp. 206-211.

20. Troshin, A.G. and Nzioka, A.M., Ukrainian Patent $83321 \mathrm{C} 1,2013$.

21. Strumillo, C. and Kudra, T., Drying: Principles, Applications and Design, New York: Gordon and Breach, 1986.

22. Keey, R.B., Drying of Loose and Particulate Materials, New York: Hemisphere, 1992.

23. Athanasopolous, G.A., Laboratory testing of municipal solid waste, Proc. 2008 Int. Symp. on Waste Mechanics, New Orleans, La., 2008, p. 195.

24. Sazhin, B.S., Osnovy tekhniki sushki (Principles of Drying Engineering), Moscow: Khimiya ,1984. 